\title{
Determinants of Efficiency and Productivity in German Property-Liability Insurance: Evidence for 1995-2006
}

\author{
Michael Luhnen
}

Institute of Insurance Economics, University of St. Gallen, Kirchlistrasse 2, St. Gallen 9010, Switzerland.

This paper provides a comprehensive analysis of efficiency and productivity in the German property-liability insurance industry, a market that has experienced significant change in recent years. Using data envelopment analysis (DEA) and covering the period 1995-2006, we find that there is potential for the market to improve by about 20 percentage points in terms of technical efficiency and about 50 percentage points in terms of cost efficiency. Furthermore, the analysis shows moderate total factor productivity growth and low efficiency growth during the sample period. A major contribution of the paper is its analysis of six efficiency determinants - firm size, distribution channels, ownership forms, product specialisation, financial leverage and premium growth - using a truncated regression and bootstrapping approach to avoid invalid inference.

The Geneva Papers (2009) 34, 483-505. doi:10.1057/gpp.2009.10

Keywords: data envelopment analysis; bootstrapping; Malmquist Index; Germany; property-liability insurance

\section{Introduction}

Market liberalisation in the European insurance industry, which began in the mid1990s with the Third Generation Insurance Directive (1994), has led to a significant change in the industry's landscape and dynamics. Regulatory obstacles to free competition within national markets and between those markets were removed in an effort to reduce prices and improve customer choice. As a consequence, firms and markets were expected to become more efficient and more productive. ${ }^{1}$

The German insurance market, historically one of the most tightly regulated national markets in the European Union, was particularly affected by the deregulation. $^{2}$ For example, a fierce price competition erupted in the German motor insurance industry in the years after $1994 .{ }^{3}$ That is also why there are quite a few studies on the development and determinants of efficiency and productivity in Germany during and following the 1990s. ${ }^{4}$ While all these studies focus on the German insurance market in general or on life insurance in particular, there is only one study by Wende et al..$^{5}$ that looks specifically at the property-liability market. However, this

\footnotetext{
${ }^{1}$ Rees et al. (1999); Cummins and Rubio-Misas (2006).

${ }^{2}$ Hussels and Ward (2006).

${ }^{3}$ Eling and Luhnen (2008a).

${ }^{4}$ For example Mahlberg (1999); Mahlberg (2000); Mahlberg and Url (2000); Hussels and Ward (2006).

${ }^{5}$ Wende et al. (2008).
} 
study is based on a relatively small data set of 40 companies and investigates a very specific research question regarding organisational form and efficiency.

Therefore, the aim of this paper is to provide a comprehensive evaluation of efficiency and productivity in the German property-liability insurance industry for the period 1995-2006 based on a large sample of 295 companies. We contribute to the existing literature in the following ways: first, using data envelopment analysis (DEA) we provide different efficiency scores - cost, technical, allocative, scale - and therefore identify different areas of efficiency improvement for the German property-liability industry. Second, the change in efficiency and productivity over time is analysed, using the Malmquist Index of Total Factor Productivity, to discover how deregulation affected both. Third, the influence on firm efficiency of different factors, such as firm size, distribution channels, ownership forms, product specialisation, financial leverage and premium growth, is determined. This analysis is of particular interest to both regulators and managers, as it provides answers to important economic questions: for example, whether further market consolidation (through mergers and acquisitions) is desirable from an efficiency point of view or whether insurers should focus their sales activities on certain channels in order to efficiently provide products to customers. Lastly, on the methodological side, this paper is the first to empirically apply to the insurance industry the single bootstrap algorithm proposed by Simar and Wilson ${ }^{6}$ for the regression of contextual variables on efficiency, permitting valid inference. Our study thus provides a methodologically robust analysis of efficiency determinants.

The analysis reveals that there is significant potential for the German propertyliability insurance industry to improve cost efficiency (CE) (by about 50 percentage points) and technical efficiency (TE) (by about 20 percentage points). Furthermore, there is moderate total factor productivity (TFP) growth of 8.2 per cent and slight efficiency growth of 0.3 per cent for the period 1995-2006, showing a positive impact of deregulatory efforts on efficiency and productivity. Other markets, such as Spain or Portugal, show similar TFP growth levels. ${ }^{7}$ With regard to the determinants of efficiency, we find a strong positive relationship between firm size and efficiency. The analysis of different distribution systems shows that exclusive agent insurers are significantly more efficient than independent agent insurers, which is in line with existing findings for other countries such as the United Kingdom and the United States. ${ }^{8}$ Regarding the relationship between efficiency and organisational form, we find mutuals more efficient than stocks. Our analysis supports the strategic focus hypothesis, as specialised insurers are more cost efficient than diversified insurers. This finding is in line with Cummins et al., ${ }^{9}$ who analyse economies of scope for the U.S. insurance market. Finally, we find a positive relationship between leverage and efficiency and a negative relationship between premium growth and efficiency.

The remainder of the paper is organised as follows. In the next section, our hypotheses are presented together with an overview of existing studies. The subsequent

\footnotetext{
${ }^{6}$ Simar and Wilson (2007).

${ }^{7}$ Cummins and Rubio-Misas (2006); Barros et al. (2005).

${ }^{8}$ Berger et al. (1997); Klumpes (2004).

${ }^{9}$ Cummins et al. (2007).
} 
section outlines the methodology and data used in the paper. In the penultimate section, we present and discuss the results of our empirical analysis and the final section summarises results and highlights areas for future research.

\section{Hypotheses and previous evidence}

In this section, we shortly discuss the main hypotheses to be tested in the empirical part and give an overview of existing literature.

Hypothesis and related literature on the development of efficiency and productivity in Germany following deregulation

H1: Efficiency and productivity have increased in the German property-liability market following deregulation

Following the deregulation in the German insurance market in 1994, insurance companies were expected to become more efficient and more productive: efficient firms, which previously could not exploit their advantages due to regulatory obstacles, gain market share and realise economies of scale. Inefficient firms are forced to improve efficiency or be taken over by more efficient firms. As a result, efficiency and productivity in the German property-liability market should increase over time.

This development has already been observed in studies on the whole German market as well as on life insurance: for example, Mahlberg ${ }^{10}$ and Mahlberg and Url ${ }^{11}$ find for the whole German market and the period 1992-1996 an increase in productivity by 12 per cent, with a slight decrease in technical efficiency and moderate technical progress. Hussels and Ward $^{12}$ use data from 1991-2002 and focus on the German life insurance market. They find relatively low levels of average technical (0.76) and cost (0.56) efficiency. The TFP growth of 2.7 per cent is mainly driven by technological change ( 2.2 per cent) and only to a limited extent by efficiency change ( 0.5 per cent). Trigo Gamarra ${ }^{13}$ uses a different frontier efficiency methodology stochastic frontier analysis (SFA) instead of DEA - and an unbalanced panel data set containing more firms, covering the period 1995-2002 for life insurance. She also finds positive TFP growth and, moreover, stable cost and profit efficiencies, combined with positive scale efficiency (SE) changes. Finally, Trigo Gamarra and Growitsch ${ }^{14}$ analyse the German life insurance market with a focus on the relationship between distribution strategies and cost and profit efficiency. They find economic evidence for the absence of performance advantages of insurers with specialised distribution systems. Thus they explain the declining significance of distribution systems that rely only on exclusive agents and the increasing importance of multi-channel insurers following deregulation.

\footnotetext{
${ }^{10}$ Mahlberg (1999); Mahlberg (2000).

${ }^{11}$ Mahlberg and Url (2000).

${ }^{12}$ Hussels and Ward (2006).

13 Trigo Gamarra (2008a).

14 Trigo Gamarra and Growitsch (2008).
} 
Studies on other European markets have also shown that the 1994 deregulation has led to an improvement in efficiency and productivity: for example, Cummins and Rubio-Misas ${ }^{15}$ find average TFP growth of 8.7 per cent for 1989-1998 in the Spanish market, and Barros et al. ${ }^{16}$ of 11.3 per cent for 1995-2001 in the Portuguese market. Also Turchetti and Daraio ${ }^{17}$ find that the European deregulation process significantly affected the Italian motor insurance industry in terms of productivity.

\section{Hypotheses and related literature on determinants of efficiency}

One focus of the paper is the analysis of six efficiency determinants. In the following, we discuss our hypotheses on how the six contextual variables that are focus of the empirical investigation in the section entitled 'Analysis of efficiency determinants' influence efficiency.

H2: There is a positive relationship between size and efficiency

Many frontier efficiency studies in insurance have found a positive relationship between size and efficiency, which can be explained by large insurers' significant scale advantages with regard to the production technology. ${ }^{18}$ We assume the same to be true for the German property-liability industry.

H3: Exclusive agent insurers are more efficient than independent agent insurers

The use of independent agents is known to be costly for insurance companies as total cost, mainly driven by high commission payments to ensure the sale of own products, is higher than for the exclusive agent channel. ${ }^{19}$ In recent studies, Klumpes ${ }^{20}$ finds for the U.K. life insurance industry that independent agent firms are less cost efficient than insurers using appointed or company representatives. Berger et al. ${ }^{21}$ in an analysis of the U.S. property-liability market, come to a similar conclusion. They additionally analyse profit efficiency differences between the two distribution forms and find that the cost efficiency difference is not sustained: independent agent firms are less cost efficient than exclusive agent firms, but they are able to produce higher quality outputs and are compensated by higher revenues. Trigo-Gamarra ${ }^{22}$ in a study on the German market also shows that independent agents deliver a higher level of service quality than exclusive agents.

H4: Stock insurers are more efficient than mutual insurers (expense preference hypothesis)

There are two principal hypotheses regarding the effect of ownership on efficiency: the expense preference hypothesis and the managerial discretion hypothesis. ${ }^{23}$

\footnotetext{
${ }^{15}$ Cummins and Rubio-Misas (2006).

16 Barros et al. (2005).

17 Turchetti and Daraio (2004).

${ }^{18}$ For example Cummins and Zi (1998); Cummins and Rubio-Misas (2006).

${ }^{19}$ Cummins and van Derhei (1979).

${ }^{20}$ Klumpes (2004).

21 Berger et al. (1997).

22 Trigo Gamarra (2008b).

${ }^{23}$ Mester (1991); Mayers and Smith (1988).
} 
According to the expense preference hypothesis, mutual insurers are less efficient than stock companies because they have higher perquisite consumption by managers. The managerial discretion hypothesis suggests that mutual and stock insurers use different technologies and that mutual companies are more efficient in lines of business with relatively low managerial discretion. The empirical evidence on these two hypotheses with regard to insurance companies is mixed. However, most studies conclude that stock companies are more efficient than mutuals and thus confirm the expense preference hypothesis. ${ }^{24}$ Some studies find mutuals more efficient than stocks or at least equally efficient: for example, Diacon et al., ${ }^{25}$ in a comparison of 15 European countries, find higher levels of technical efficiency for mutuals than for stocks. Greene and Segal, ${ }^{26}$ in an application to the U.S. life insurance industry, suggest that mutual companies are as cost efficient as stock companies.

H5: Specialised insurers are more efficient than diversified insurers (strategic focus hypothesis)

The two main hypotheses regarding specialisation are the conglomeration and the strategic focus hypothesis. ${ }^{27}$ The first hypothesis implies that firms active in several lines of business can profit from economies of scope due to cost and revenue complementarities (e.g. sharing of inputs, earnings diversification, cross selling). The second hypothesis suggests that conglomeration leads to diseconomies of scale (e.g. due to increased coordination cost or lack of specialised expertise). Cummins et al. ${ }^{28}$ analyse economies of scope for the U.S. insurance market and compare insurers operating in both life-health and property-liability insurance to those specialising in one of the two businesses. They find only weak evidence for economies of scope and thus conclude that a strategy of strategic focus is superior to a diversification strategy.

H6: There is a positive relationship between leverage and efficiency

The relationship between leverage and efficiency should be positive, that is higher leverage means higher degrees of efficiency, but only up to a certain, optimal equity to assets ratio. This is shown in a study by Cummins and Nini, ${ }^{29}$ who find that insurers significantly over-utilise equity capital as an input.

H7: Premium growth and efficiency are negatively related

To our knowledge, the short-term relationship between premium growth and efficiency has not yet been analysed for the insurance industry. We hypothesise that this relationship is negative as the efficiency effect of the short-term increase in business volume might often be outweighed by heavy investments in creating that growth (e.g. costly marketing campaigns, which increase operating expenses).

\footnotetext{
${ }^{24}$ For example Erhemjamts and Leverty (2007) for the U.S. market; Diboky and Ubl (2007) for the German market.

${ }^{25}$ Diacon et al. (2002).

${ }^{26}$ Greene and Segal (2004).

${ }^{27}$ Cummins et al. (2007).

${ }^{28}$ Cummins et al. (2007).

${ }^{29}$ Cummins and Nini (2002).
} 
Also, fast growing insurers often lack underwriting discipline and attract bad risks, which turn out to be costly.

\section{Methodology and data}

\section{Methodology}

$D E A$

There are two principal approaches to frontier efficiency measurement: DEA, which is a mathematical programming approach, and SFA, which is an econometric approach. Both approaches have their advantages and disadvantages, but DEA is the most commonly used method in papers analysing frontier efficiency in the insurance industry. Following Cummins et al. ${ }^{30}$ we also use DEA for this study for three main reasons. First, DEA is particularly convenient for decomposing cost and technical efficiency into its components. Second, the Malmquist Index of Total Factor Productivity, which is one of the most commonly used methods for measuring the development of efficiency and productivity over time, is typically DEA based. ${ }^{31}$ Third, DEA solves the optimisation problem separately for each decision-making unit in the sample. This allows us to calculate economies of scale for specific units - insurance companies in our case - whereas econometric estimates of scale economies rely on the same parameter estimates for all units.

DEA is a non-parametric optimisation approach that employs linear programming to construct an efficient frontier that envelopes all input-output combinations of firms in the sample. Efficient firms' input-output combinations are situated on the envelope, that is on the efficient frontier, while inefficient firms' input-output combinations are below the frontier. All firms' input-output combinations are benchmarked against those of the efficient frontier firms, which are assigned an efficiency score of 1 . The other, less efficient firms, receive a score of less than 1, but no lower than 0. Different types of efficient frontiers can be estimated. In the simplest case, a production frontier is estimated, assuming that companies minimise inputs conditional on given output levels (input orientation) or maximise outputs conditional on given input levels (output orientation). DEA is also capable of being specified under different assumptions regarding returns to scale. In the case of constant returns to scale (CRS), all firms are assumed to operate at optimal scale. The increase of inputs results in a proportional increase of outputs. However, in reality, firms often do not operate at optimal scale. To account for this situation, DEA can be specified for variable returns to scale (VRS), meaning that input increases result in disproportional output increases. For a detailed explanation of the DEA methodology, the reader is referred to Cooper et al. ${ }^{32}$

In our study, efficiency values are calculated assuming input orientation and VRS. Different types of efficiency are calculated. Technical efficiency is analysed in order to

\footnotetext{
${ }^{30}$ Cummins et al. (1999).

${ }^{31}$ Fuentes et al. (2001) have also developed a parametric distance function approach, which allows calculating the Malmquist Index based on econometric approaches, such as SFA.

${ }^{32}$ Cooper et al. (2007).
} 
see whether a firm operates with the best available technology as represented by the VRS frontier. The degree of scale efficiency of a firm shows whether it is conducting its operations at the optimal scale as represented by the CRS frontier. Cost efficiency measures whether a firm operates at minimum possible costs, and can be decomposed into technical and allocative efficiency (allocative efficiency), the latter indicating whether firms choose the optimal mix of input factors at given prices and production technology.

\section{Malmquist Index of Total Factor Productivity}

TFP is defined as an index of output quantities divided by input quantities. TFP growth is defined as the change in outputs net of the change in input usage. There are two principal sources of TFP growth: technical change - that is a shift in the production frontier between two periods due to an improvement in the production technology - and technical efficiency change - that is a change in the distance of a firm to the efficient frontier between two periods, irrespective of a change in the position of the frontier itself. Technical efficiency change can be further broken down into pure technical efficiency change (relative to the VRS frontier) and scale efficiency change.

In this study, we use the input-oriented Malmquist Index of TFP to calculate TFP growth, technical change, technical efficiency change, pure technical efficiency change and scale efficiency change. These measures are useful in evaluating the development of efficiency and productivity in the German property-liability insurance market over time. For the definition of the input-oriented Malmquist Index, we follow Färe and Grosskopf: ${ }^{33}$ a ratio of the index of $<1$ indicates a favourable development (e.g. a positive growth in TFP between two periods as the input levels from the second period are closer to the efficient frontier than those from the first period for producing the corresponding amounts of outputs); a value of $>1$ is a negative development (e.g. a decline in TFP between two periods). ${ }^{34}$

\section{Regression of contextual variables on efficiency scores}

To determine the effects of contextual variables - such as ownership form or distribution systems - on firm efficiency, many studies employ a two-stage approach: in the first stage, efficiency scores are estimated and then, in the second stage, they are regressed on a set of covariates represented by the contextual variables that might affect firm performance. Most studies have specified a censored (tobit) model for the second stage. However, censored models have several shortcomings, the most important being that conventional approaches to inference are used, which are invalid due to complicated and unknown serial correlations among estimated efficiency scores. In the two-stage analysis used in this paper, we avoid the inference

\footnotetext{
${ }^{33}$ Färe and Grosskopf (1996).

${ }^{34}$ Some authors define the input-oriented Malmquist Index as the reciprocal of the Index used in this paper. In this definition, an Index value of $>1(<1)$ indicates productivity growth (decline). We decided to stay with the standard definition by Färe and Grosskopf (1996).
} 
problem by using the procedure designed by Simar and Wilson. ${ }^{35}$ This procedure involves a truncated regression of contextual variables on efficiency estimates, which is followed by bootstrapping and re-estimation of the regression coefficients. The procedure was implemented using the software package FEAR 1.11 and the statistical software $\mathrm{R} .{ }^{36}$ For a formal representation of the procedure, the reader is referred to the Appendix.

\section{Data}

The data used in the empirical investigation was obtained from the Hoppenstedt insurer database and complemented by data from annual reports of insurance companies. The sample consists of 295 German property-liability insurers with data on 2,747 firm years for the period $1995-2006 \cdot{ }^{37}$ It accounts for 97 per cent (91 per cent) of the entire German property-liability market in terms of premiums of the year 1995 (2006). The use of this unbalanced panel data set allows a comprehensive evaluation of efficiency and productivity of the German property-liability industry, as it also includes firms that entered or left the market during the sample period.

\section{Inputs and input prices}

Researchers are in general agreement as to the choice of input factors for frontier efficiency measurement in insurance: most studies use labour, business services and capital. ${ }^{38}$ As precise data on labour and business services is not available for the German property-liability market, these two input categories are combined into one input category. The quantity of labour and business services input is then proxied by dividing operational expenditures for each year and each insurer by an annual wage variable for the German insurance sector (price of labour). We obtained the wage variable from the Genesis database of the German Federal Statistical Office. ${ }^{39}$ Many other frontier efficiency studies use a similar procedure. ${ }^{40}$ Following recent frontier efficiency studies, we use two capital inputs: equity and debt capital, the latter being proxied by technical provisions net of reinsurance. The price of debt capital is obtained using the 10-year average return of the Deutscher Rentenindex, which is a representative cross-section of German government bonds. The price of equity capital should be considered on a firm-specific basis. However, due to limited data availability on German insurance companies, especially mutual insurers, all firms are assumed to have the same price of equity capital for a given year. The price of equity capital is

\footnotetext{
${ }^{35}$ Simar and Wilson (2007).

${ }^{36}$ Wilson (2008a) for an explanation of both.

${ }^{37}$ The initial sample consisted of 296 insurers, covering 2,793 firm years. A total of 46 firm years had to be removed, as they did not display all inputs and outputs required for the analysis.

${ }^{38}$ See Cummins and Weiss (2000); Eling and Luhnen (2008b) for an overview of input and output usage in frontier efficiency studies on insurance.

${ }^{39}$ www-genesis.destatis.de/genesis/online.

${ }^{40}$ For example Diacon et al. (2002); Fenn et al. (2008).
} 
consequently defined using the 10-year average return of the German primary stock index Deutscher Aktienindex. The 10-year averages are used in order to avoid negative prices and yield stable price levels, a method also used by Cummins et $a l^{41}$ and Diboky and $\mathrm{Ubl}^{42}{ }^{4}$ who also use multi-year averages in their price calculations. The data for both indices were obtained from the German Stock Exchange (Deutsche Börse). For the sake of comparability, all input variables were deflated to the base year 1995 using the German Consumer Price Index, which was obtained from the Genesis database of the German Federal Statistical Office.

\section{Outputs}

For the choice of outputs, we use the value-added approach, a well-established standard in literature. According to this approach, the insurance company is assumed to provide three main services, which need to be proxied by appropriate variables: (1) risk pooling and risk bearing; (2) financial services relating to insured losses and (3) intermediation. We proxy the first two services by the claims incurred net of reinsurance, following Cummins and Weiss. ${ }^{43}$ An alternative would be to use premiums instead to proxy the risk-pooling/risk-bearing and financial services activities of insurers, however, this proxy has been criticised for representing price times quantity of output and not output. ${ }^{44}$ The output variable used as a proxy for the intermediation function is total invested assets. To obtain present values, all output variables are deflated, again using the German Consumer Price Index.

\section{Summary statistics}

Table 1 provides summary statistics for all input, output and price variables used in the empirical study. We employ three inputs (labour and business service, debt capital and equity capital) and two outputs (claims incurred net of reinsurance and total invested assets).

\section{Empirical analysis}

In the first part of this chapter, we present different efficiency scores from our DEA analysis for the period 1995-2006 and evidence on returns to scale. Since efficient frontiers were estimated for each single year in the DEA analysis, one cannot draw conclusions with regard to the development of efficiency over time based on the results presented below. Therefore, in the second part of the chapter, the Malmquist Index of Total Factor Productivity is calculated in order to achieve some insight into the development of efficiency and productivity over time. In the last part of this section, results from the empirical analysis of efficiency determinants are presented.

\footnotetext{
${ }^{41}$ Cummins et al. (2004).

${ }^{42}$ Diboky and Ubl (2007).

${ }^{43}$ Cummins and Weiss (2000).

44 Yuengert (1993).
} 
The Geneva Papers on Risk and Insurance - Issues and Practice

492

Table 1 Summary statistics for inputs, input prices and outputs

\begin{tabular}{llrrrr}
\hline Variable & \multicolumn{1}{c}{ Unit } & Mean & St. Dev. & Min. & Max. \\
\hline Inputs & & & & & \\
$\quad$ Labour and business service & Quantity & $1,050.81$ & $2,565.05$ & 0.00 & $36,782.55$ \\
$\quad$ Debt capital & Million EUR & 387.72 & $1,136.83$ & 0.00 & $19,220.83$ \\
$\quad$ Equity capital & Million EUR & 93.52 & 218.38 & 0.13 & $2,316.05$ \\
Input prices & & & & & \\
$\quad$ Price of labour & EUR & $56,893.00$ & $2,123.00$ & $52,797.00$ & $58,938.00$ \\
Price of debt capital & Per cent & 7.26 & 0.94 & 5.25 & 8.37 \\
$\quad$ Price of equity capital & Per cent & 13.29 & 3.47 & 7.78 & 18.20 \\
Outputs & & & & & \\
$\quad$ Claims incurred & Million EUR & 150.77 & 370.77 & 0.00 & $5,354.80$ \\
$\quad$ Total invested assets & Million EUR & 404.29 & $1,117.00$ & 0.12 & $19,650.60$ \\
\hline
\end{tabular}

Table 2 Efficiency scores

\begin{tabular}{lccccc}
\hline Year & $\begin{array}{c}\text { No. of } \\
\text { Firms }\end{array}$ & $\begin{array}{c}\text { Cost } \\
\text { efficiency }(C E)\end{array}$ & $\begin{array}{c}\text { Technical } \\
\text { efficiency }(\text { TE) }\end{array}$ & $\begin{array}{c}\text { Allocative } \\
\text { efficiency (AE) }\end{array}$ & $\begin{array}{c}\text { Scale } \\
\text { efficiency (SE) }\end{array}$ \\
\hline 1995 & 239 & 0.31 & 0.75 & 0.41 & 0.94 \\
1996 & 240 & 0.33 & 0.77 & 0.42 & 0.93 \\
1997 & 241 & 0.49 & 0.81 & 0.60 & 0.89 \\
1998 & 239 & 0.50 & 0.81 & 0.61 & 0.91 \\
1999 & 239 & 0.45 & 0.78 & 0.57 & 0.91 \\
2000 & 232 & 0.54 & 0.78 & 0.68 & 0.90 \\
2001 & 232 & 0.52 & 0.77 & 0.67 & 0.98 \\
2002 & 230 & 0.55 & 0.81 & 0.66 & 0.92 \\
2003 & 224 & 0.54 & 0.83 & 0.64 & 0.92 \\
2004 & 217 & 0.56 & 0.83 & 0.67 & 0.85 \\
2005 & 211 & 0.51 & 0.79 & 0.63 & 0.91 \\
2006 & 203 & 0.52 & 0.84 & 0.61 & 0.90 \\
& & & & &
\end{tabular}

\section{Efficiency scores and returns to scale}

Table 2 presents mean values for various DEA efficiency measures for the years 1995-2006. Cost efficiency scores (Column 3) for our sample range between 0.31 and 0.56 , with a mean of 0.48 . This indicates that the average German property-liability insurer could improve its cost efficiency on average by 44-69 percentage points in order to be as cost efficient as the best insurers in the sample. This result is in line with the cost efficiency scores for the German life insurance market of $0.50-0.60$ found by Hussels and Ward ${ }^{45}$ and Trigo Gamarra and Growitsch. ${ }^{46}$ However, it is

\footnotetext{
${ }^{45}$ Hussels and Ward (2006).

46 Trigo Gamarra and Growitsch (2008).
} 
significantly lower than those found by Wende et al. ${ }^{47}$ for the property-liability market. Their scores range between 0.84 and 0.98 depending on the year and organisational form considered. This difference is possibly due to their significantly smaller sample of only 40 insurance companies.

Splitting cost efficiency into its components, we see that technical efficiency, under assumption of VRS (Column 4), ranges between 0.75 and 0.84 and allocative efficiency (Column 5) is between 0.41 and 0.68 . Although average technical efficiency, at a value of 0.80 , is already on a high level, there is still room for improvement for many insurers to upgrade their technology to state-of-the art, for example through improved information technology in claims management or tariff calculation. This is especially important in order to stay competitive in times of rapid technological change. The more severe source of cost inefficiency, however, is allocative inefficiency. The mean score of only 0.59 suggests that German property-liability insurers could significantly contribute to an improvement of cost efficiency by doing a better job in choosing cost minimising input combinations. Comparing for each firm and year the use of actual input quantities vs. optimal input quantities reveals that labour inputs are most severely over-utilised, followed by debt and equity capital. ${ }^{48}$ Both the technical efficiency and allocative efficiency scores found here again agree with the results by Hussels and Ward for the life market. The technical efficiency scores computed by Wende et al. are higher than our scores by approximately 15 percentage points, again possibly due to their smaller sample.

Average scale efficiency values (Column 6) for the different years range between 0.85 and 0.94 with a mean of 0.90 , indicating on average that there is less efficiency loss due to scale inefficiency in the German property-liability industry. Nevertheless, it has to be noted that scale efficiency scores for individual firms are as low as 0.25 at the minimum. As the scale efficiency measure does not show the nature of scale inefficiencies for a particular firm, that is whether it is due to increasing or decreasing returns to scale, ${ }^{49}$ we calculated returns to scale for each firm in the sample. The results are displayed in Table 3, where the companies have been sorted into three size classes, each containing an equal number of companies, according to their total assets. ${ }^{50}$ For each size class, the share of companies in the size group operating under constant returns to scale (CRS; Column 2), decreasing returns to scale (DRS; Column 3) and increasing returns to scale (IRS; Column 4) has been calculated.

Companies operating under CRS are of optimal size with no scale inefficiencies. This is the case for 18 per cent of the small firms, but only 14 per cent and 7 per cent of

\footnotetext{
${ }^{47}$ Wende et al. (2008).

${ }^{48}$ Most allocative inefficiencies in the sample could be removed, depending on the individual firm situation, by adapting one of the three following major strategies, sorted by frequency of occurrence: (1) Increase equity capital and reduce labour and debt capital; (2) Increase debt capital and reduce labour and equity capital; (3) Increase labour and reduce debt and equity capital. Results of this analysis are available from the author upon request.

${ }^{49}$ Coelli et al. (2005).

${ }^{50}$ Total assets is a widely used measure of insurer size. To be able to compare different-size companies, we thus sort all companies by their total assets into large (total assets larger than EUR 218 million), medium and small (total assets smaller than EUR 35 million).
} 
Table 3 Returns to scale

\begin{tabular}{lccc}
\hline $\begin{array}{l}\text { Size } \\
\text { class }\end{array}$ & $\begin{array}{c}\text { Constant returns to scale } \\
(\text { CRS })(\%)\end{array}$ & $\begin{array}{c}\text { Decreasing returns to scale } \\
(\text { DRS })(\%)\end{array}$ & $\begin{array}{c}\text { Increasing returns } \\
\text { to scale }(\text { IRS })(\%)\end{array}$ \\
\hline Large & 7 & 91 & 2 \\
Medium & 14 & 75 & 11 \\
Small & 18 & 21 & 61 \\
\hline
\end{tabular}

medium-sized and large insurers, respectively. DRS indicate that companies are not operating at the optimal scale and that an increase in the size of operations will lead to disproportionately low additional returns, a situation that is found in the case of many of the large and medium-sized insurers (91 per cent and 75 per cent, respectively). IRS implies that firms are not operating at an optimal scale, but that they could achieve disproportionately high additional returns by increasing the size of their operations. This is especially the case for small insurers in the sample (61 per cent). These results are in line with what has been found for other insurance markets. ${ }^{51}$ We can draw important implications for possible merger activities in the market: while efficiency can be improved through returns to scale gains in case of mergers between small and, to a certain extent, medium-sized insurers, this is not the case for large insurers. However, due to the already high level of scale efficiency in the German market, even the potential efficiency gains from merger for small insurers are somewhat limited.

\section{Development of efficiency and productivity over time}

To evaluate the development of efficiency and productivity over time, we calculated the input-oriented Malmquist Index of TFP. The results are displayed in Table 4. TFP change (Column 6) is broken down into technical change (Column 2) and technical efficiency change (Column 3), the latter of which is again split into pure technical efficiency change (Column 4) and scale efficiency change (Column 5). The last line of Table 4 displays changes for the entire period (1995-2006), whereas the preceding lines display changes from one year to the next, for example from 1995 to 1996 (marked as 1995/1996).

The last line of Table 4 shows that TFP change over the entire period (1995-2006) is positive with an increase of 8.2 per cent between 1995 and 2006. The development is mainly attributable to a positive technical change $(+7.9$ per cent $)$, which means that the production frontier has shifted due to a significant improvement in the production technology over time.

Technical efficiency stayed almost stable, when comparing 2006 with $1995(+0.3$ per cent), which means that the relative distance to the production frontier has not changed much. Firms have not taken advantage of the technological change to further upgrade their operating performance relative to their peers. The main reason for this is the decrease in scale efficiency, which has, however, been offset by the pure technical

${ }^{51}$ For example Hardwick (1997) for the U.K.; Fecher et al. (1991) for France; Yuengert (1993) and Cummins and $\mathrm{Zi}$ (1998) for the U.S. 
Table 4 Malmquist Index of Total Factor Productivity

\begin{tabular}{lccccc}
\hline Period & $\begin{array}{c}\text { Technical } \\
\text { change }\end{array}$ & $\begin{array}{c}\text { Technical } \\
\text { efficiency change }\end{array}$ & $\begin{array}{c}\text { Pure technical } \\
\text { efficiency change }\end{array}$ & $\begin{array}{c}\text { Scale efficiency } \\
\text { change }\end{array}$ & $\begin{array}{c}\text { Total factor } \\
\text { productivity change }\end{array}$ \\
\hline $1995 / 1996$ & 1.004 & 0.980 & 0.977 & 1.004 & 0.983 \\
$1996 / 1997$ & 1.034 & 1.015 & 0.996 & 1.019 & 1.040 \\
$1997 / 1998$ & 1.029 & 0.980 & 1.001 & 0.979 & 1.005 \\
$1998 / 1999$ & 0.970 & 1.050 & 1.040 & 1.010 & 0.997 \\
$1999 / 2000$ & 0.926 & 1.108 & 1.061 & 1.045 & 1.013 \\
$2000 / 2001$ & 0.949 & 1.079 & 1.035 & 1.045 & 1.009 \\
$2001 / 2002$ & 1.001 & 0.983 & 0.997 & 0.990 & 0.995 \\
$2002 / 2003$ & 1.026 & 0.978 & 0.988 & 0.994 & 0.995 \\
$2003 / 2004$ & 0.990 & 1.021 & 1.007 & 0.997 & 0.999 \\
$2004 / 2005$ & 0.882 & 1.153 & 1.066 & 1.085 & 1.083 \\
$2005 / 2006$ & 1.228 & 0.882 & 0.934 & 0.937 & 0.918 \\
$1995 / 2006$ & 0.921 & 0.997 & 0.967 & 1.032 & \\
\hline
\end{tabular}

efficiency increase of roughly the same amount. This suggests that firms have, on average, not managed to change their operations to an optimal scale (e.g. small firms merge with other small or medium-sized entities). Overall, it seems as if the deregulatory efforts in the German insurance market since 1994 have had a beneficial impact, as productivity and efficiency increased, as intended by the regulators. This result is in line with those of other studies on TFP in European insurance markets (see Hypothesis 1).

Looking at the by-year changes in TFP shown in Table 4, one sees that there is no steady TFP growth over the years: positive TFP changes in 1995/1996, 1998/1999 and $2001 / 2002$ are always followed by one or two periods of TFP decline. However, there is no clear pattern as to the factors driving this TFP decline. In some periods it is mainly due to negative technical change (e.g. 1996/1997, 1997/1998); in others it is mainly due to negative technical efficiency change (e.g. 1999/2000, 2000/2001).

\section{Analysis of efficiency determinants}

In this section, the following six contextual variables are analysed with regard to their influence on the efficiency of German property-liability insurers: (1) size; (2) distribution channels; (3) ownership forms; (4) product specialisation; (5) financial leverage; and (6) premium growth. In a first step, for each contextual variable, the firms are grouped according to variable characteristics (e.g. small, medium and large in the case of size). Then, average technical efficiency and cost efficiency values are calculated for each characteristic. Additionally, a simple pair-wise $t$-test is performed in order to determine whether the calculated means for the different characteristics are statistically different from each other.

However, the results of this simple analysis must be viewed with caution, as they always show combined effects for each variable, for example the efficiency of small insurers given their ownership form, distribution channel and product specialisation. To isolate the impact of each contextual variable on efficiency scores, in a second step, 
Table 5 Overview of contextual variables

\begin{tabular}{|c|c|c|c|}
\hline Variable & Characteristics & Explanation & $\begin{array}{l}\text { Coding in } \\
\text { truncated regression }\end{array}$ \\
\hline \multirow[t]{3}{*}{ Size } & Large & Total assets & $\ln$ (assets)/mean $\ln$ (assets) \\
\hline & Medium & Total assets & \\
\hline & Small & Total assets & \\
\hline \multirow{3}{*}{$\begin{array}{l}\text { Distribution } \\
\text { channels }\end{array}$} & Exclusive agents & Employed, self-employed, banks & 0 \\
\hline & Direct & Website, phone & 0 \\
\hline & Independent agents & Brokers, independent advisors & 1 \\
\hline \multirow[t]{3}{*}{ Ownership } & Mutual & - & 0 \\
\hline & Public & - & 0 \\
\hline & Stock & - & 1 \\
\hline \multirow[t]{2}{*}{ Specialisation } & Specialised & $\begin{array}{l}\text { More than two-third of premiums } \\
\text { in one line of business }\end{array}$ & 1 \\
\hline & Non-specialised & Otherwise & 0 \\
\hline \multirow[t]{2}{*}{ Leverage } & $\begin{array}{l}\text { Leverage above } \\
\text { median }\end{array}$ & Equity/assets below median & 1 \\
\hline & $\begin{array}{l}\text { Leverage below } \\
\text { median }\end{array}$ & Otherwise & 0 \\
\hline \multirow[t]{2}{*}{ Growth } & Growth above median & $\begin{array}{l}\text { Premium growth } \\
\text { above median }\end{array}$ & 1 \\
\hline & Growth below median & Otherwise & 0 \\
\hline
\end{tabular}

a truncated regression analysis of the variables on efficiency is performed. We use the bootstrapping Algorithm \#1 as proposed by Simar and Wilson ${ }^{52}$ and introduced in the methodology section of this paper.

The characteristics of the six contextual variables are as follows (for an overview, see Table 5). For size, the sample is divided evenly into small, medium and large companies according to total assets. The sample is divided into three types of distribution channels: exclusive agent, independent agent and direct insurers. Exclusive agent insurers either employ their sales force directly or have exclusive contracts with self-employed salespersons. Distribution through banks is also included in the exclusive agent category, as most banks in Germany typically distribute the products of one cooperation partner (e.g. German cooperative banks exclusively distribute the products of $\mathrm{R}+\mathrm{V}$ Insurance). Independent agent insurers use brokers and independent financial advisors to distribute their products, whereas direct insurers distribute through their own websites or by phone. As most insurers in the German market use multiple distribution channels, we assigned each company to one of the three categories based on which category accounted for the majority of their sales.

\footnotetext{
${ }^{52}$ Simar and Wilson (2007).
} 
The information was obtained from the insurers' annual reports, websites and company presentations.

For ownership, the sample is divided into mutual, stock and public insurers. Public insurers were founded as state-owned non-profit organisations and given a monopoly to insure a certain line of business in a certain region. The 1994 deregulation put an end to these monopolies and the formerly public insurers were sold to municipal savings banks. Information on ownership was obtained from the insurers' annual reports, websites and company presentations. With regard to the factor specialisation, we chose two categories: insurers are "specialised" if more than two-thirds of their premiums in any given year are sold under only one line of business and as "nonspecialised" if this is not the case. For the factor of leverage, the sample is divided into insurers with an equity to assets ratio above the median - that is a low level of leverage - and those with an equity to assets ratio below the median - that is a high level of leverage. A similar categorisation was used for growth, with one group containing insurers with above-median premium growth and the other with below-median premium growth.

To perform the truncated regression analysis, the contextual variables are considered as independent variables and are included as follows (for an overview, see Table 5). Size is included as the logarithm of total assets, which is standardised by the mean of the logarithm of total assets. This is necessary because the independent variables in the truncated regression should be scaled so that they do not differ by too many orders of magnitude from 1 so as to be able to achieve convergence in the maximum likelihood procedure. ${ }^{53}$ Distribution channels were coded as 0 for exclusive agents and direct and as 1 for independent insurers. Ownership is coded as 0 for mutual and public insurers and 1 for stock insurers. Specialisation is coded as 1 for specialised insurers, 0 otherwise. Insurers with leverage above the median are assigned a 1 and 0 otherwise; insurers with above-median growth are attributed a 1 and 0 otherwise.

In the following, the results of our analysis of efficiency determinants are presented. Table 6 shows the results of the group comparisons. Each panel covers one contextual variable and indicates the mean technical efficiency, under the assumption of VRS and cost efficiency scores for the different variable characteristics, as well as the $t$-tests for mean difference.

Table 7 shows the results of the truncated regression analysis (Panel A for the technical efficiency and Panel B for the cost efficiency scores). As Simar and Wilson ${ }^{54}$ define their bootstrapping algorithm for efficiency values bounded between 1 and infinity - with 1 for the most efficient firm - we included the inverse of our technical efficiency and cost efficiency values - which are originally bounded between 0 and 1 into this analysis. Thus, a positive coefficient in Table 7 indicates a negative impact on efficiency and a negative coefficient indicates a positive impact on efficiency. $P$-values were calculated based on 2,000 bootstrap estimates, which were obtained for each coefficient: in case of a positive (negative) coefficient, the $p$-value is equal to 1 minus the relative share of positive (negative) bootstrap estimates, thus indicating the

\footnotetext{
${ }^{53}$ Wilson (2008b).

${ }^{54}$ Simar and Wilson (2007).
} 
Table 6 Mean efficiency scores by group

\begin{tabular}{|c|c|c|c|c|c|}
\hline & \multirow[b]{2}{*}{ Firm years } & \multicolumn{2}{|c|}{ Technical efficiency } & \multicolumn{2}{|c|}{ Cost efficiency } \\
\hline & & Mean score & $t$-test & Mean score & $t$-test \\
\hline \multicolumn{6}{|l|}{ Panel A: Size } \\
\hline Large (L) & 916 & 0.88 & $\mathrm{~L}: \mathrm{M}^{* * *}$ & 0.59 & $\mathrm{~L}: \mathrm{M}^{* * *}$ \\
\hline Medium (M) & 916 & 0.77 & $\mathrm{M}: \mathrm{S}^{*}$ & 0.45 & $\mathrm{M}: \mathrm{S}^{* * *}$ \\
\hline Small (S) & 915 & 0.75 & $\mathrm{~S}: \mathrm{L}^{* * *}$ & 0.42 & $\mathrm{~S}: \mathrm{L}^{* * *}$ \\
\hline \multicolumn{6}{|l|}{ Panel B: Distribution } \\
\hline Exclusive agents (Ex) & 1,622 & 0.81 & Ex:Di*** & 0.49 & $\mathrm{Ex}: \mathrm{Di}^{* * *}$ \\
\hline Direct (Di) & 213 & 0.82 & Di:In*** & 0.53 & Di:In*** \\
\hline Independent agents (In) & 912 & 0.77 & In:Ex*** & 0.45 & In:Ex \\
\hline \multicolumn{6}{|l|}{ Panel C: Ownership } \\
\hline Mutual (Mu) & 520 & 0.82 & Mu:P & 0.54 & Mu:P \\
\hline Public (P) & 133 & 0.78 & $\mathrm{P}: \mathrm{S}^{* *}$ & 0.50 & $\mathrm{P}: \mathrm{S} * * *$ \\
\hline Stock (S) & 2,094 & 0.79 & $\mathrm{~S}: \mathrm{Mu}^{* * *}$ & 0.47 & $\mathrm{~S}: \mathrm{Mu}^{* * *}$ \\
\hline \multicolumn{6}{|l|}{ Panel D: Specialisation } \\
\hline Specialised (Sp) & 1,371 & 0.80 & Sp:NSp & 0.50 & Sp:NSp*** \\
\hline Non-specialised (NSp) & 1,376 & 0.80 & & 0.47 & \\
\hline \multicolumn{6}{|l|}{ Panel E: Leverage } \\
\hline Above-median leverage (AL) & 1,373 & 0.83 & $\mathrm{AL}: \mathrm{BL} * * *$ & 0.51 & $\mathrm{AL}: \mathrm{BL} * * *$ \\
\hline Below-median leverage (BL) & 1,374 & 0.77 & & 0.46 & \\
\hline \multicolumn{6}{|l|}{ Panel F: Growth } \\
\hline Above-median growth (AG) & 1,373 & 0.77 & $\mathrm{AG}: \mathrm{BG}^{* * *}$ & 0.47 & $\mathrm{AG}: \mathrm{BG}^{* * *}$ \\
\hline Below-median growth (BG) & 1,374 & 0.82 & & 0.50 & \\
\hline
\end{tabular}

Note: $* * *, * * *$ indicates significance level of $10 \%, 5 \%$ and $1 \%$.

statistical significance of the sign of the coefficients. ${ }^{55}$ Confidence intervals were constructed based on the bootstrap estimates. Table 7 displays the lower and upper bounds for 95 per cent confidence intervals.

Size

As shown in Panel A of Table 6, large firms are both more technically and more cost efficient than medium-sized and small firms. These findings are in line with existing literature (see Hypothesis 2). The truncated regression analysis (Table 7) confirms the positive relationship between size and efficiency: the coefficients for technical efficiency and cost efficiency are negative and significant.

\section{Distribution}

The mean efficiency scores of the direct insurers ( 0.82 for technical efficiency and 0.53 for cost efficiency) are higher than those of the other two distribution systems, as can be seen in Panel B of Table 6. As sample sizes for the distribution types vary - there are only 213 firm years for direct insurers, but 1,622 for exclusive agents and 912 for

\footnotetext{
${ }^{55}$ For a similar approach, see, for example Afonso and Aubyn (2006).
} 
Table 7 Results of truncated regression analysis

\begin{tabular}{|c|c|c|c|c|c|}
\hline Variable & Comment & Coefficient & p-value & $\begin{array}{c}\text { CI lower } \\
\text { bound }\end{array}$ & $\begin{array}{c}\text { CI upper } \\
\text { bound }\end{array}$ \\
\hline \multicolumn{6}{|c|}{ Panel A: Technical efficiency } \\
\hline Size & $\ln ($ assets $)$-mean $\ln$ (assets) & -3.41 & 0.00 & -5.12 & 0.67 \\
\hline Distribution & $0=$ exclusive, direct $; 1=$ independent & 1.35 & 0.00 & 0.49 & 1.82 \\
\hline Ownership & $0=$ mutual, public; $1=$ stock & 1.26 & 0.01 & 0.40 & 1.82 \\
\hline Specialisation & $0=$ nonspec.; $1=$ spec & 0.01 & 0.48 & -0.33 & 0.40 \\
\hline Leverage & $0=$ below median; $1=$ above median & -2.00 & 0.01 & -2.71 & -0.76 \\
\hline Growth & $0=$ below median $; 1=$ above median & 0.91 & 0.01 & 0.32 & 1.33 \\
\hline \multicolumn{6}{|c|}{ Panel B: Cost efficiency } \\
\hline Size & $\ln ($ assets)-mean $\ln$ (assets) & -0.62 & 0.00 & -1.02 & -0.17 \\
\hline Distribution & $0=$ exclusive, direct $; 1=$ independent & 0.76 & 0.00 & 0.60 & 0.91 \\
\hline Ownership & $0=$ mutual, public; $1=$ stock & 1.46 & 0.00 & 1.16 & 1.73 \\
\hline Specialisation & $0=$ nonspec. $; 1=$ spec & -0.46 & 0.00 & -0.62 & -0.29 \\
\hline Leverage & $0=$ below median $; 1=$ above median & -1.11 & 0.00 & -1.28 & -0.92 \\
\hline Growth & $0=$ below median; $1=$ above median & 0.82 & 0.00 & 0.63 & 0.99 \\
\hline
\end{tabular}

independent agents - there is the possibility of a distortion due to sample size. DEA assigns lower efficiency scores in larger samples because there are more candidate firms for the peer group of any given firm in the case of larger samples. To assure that the higher mean efficiency value of direct insurers is not due to the small sample size, we therefore repeated the analysis using matching samples, which means that there is an equal number of direct, independent and exclusive agent firms. Additionally, the matching samples are size-stratified, meaning that all samples contain the same number of firms in each of the three size classes for each year in order to exclude any distorting effect of firm size on efficiency. ${ }^{56}$ The results confirm that insurers with a direct distribution channel are more efficient than insurers using either of the two other distribution methods. ${ }^{57}$ Comparing the results from Table 3 for exclusive agent and independent agent insurers shows that exclusive agent insurers are more efficient than independent agent insurers: efficiency scores are 0.81 vs. 0.77 for technical efficiency and 0.54 vs. 0.47 for cost efficiency.

To better understand the impact of distribution forms on efficiency, we consider the results from the truncated regression analysis in Table 7 . Here, exclusive agent insurers - grouped together with direct writers in order to use a binary dummy variable - are shown to be more technically and cost efficient than independent agent insurers: coefficients are significantly positive with $p$-values of 0 . To be confident that this result is not completely due to the direct insurers, which are more efficient than the other two distribution forms, the truncated regression is repeated excluding direct

\footnotetext{
${ }^{56}$ For a description of the matching samples approach, see Cummins et al. (2004).

57 The size-stratified matching sample contains 213 firm years for each type of distribution channel. Direct insurers have a mean technical (cost) efficiency score of $0.88(0.67)$, independent agent insurers of 0.85 $(0.57)$ and exclusive agent insurers of $0.84(0.57)$
} 
writers. The resulting comparison of independent agent insurers and exclusive agent insurers confirms that exclusive agent insurers are more technically and cost efficient than independent agent insurers; however, coefficients are smaller. ${ }^{58}$ Therefore, Hypothesis 3 is confirmed.

\section{Ownership}

Considering the results displayed in Panel C of Table 6 reveals that mutual insurers are more cost and technically efficient than stock or public insurers. The analysis was repeated using size-stratified matching samples due to the large differences in sample sizes for the different ownership forms (520 firm years for mutual, 133 for public and 2,094 for stock insurers). For both technical efficiency and cost efficiency, mutual insurers remain more efficient than the other two forms of ownership. Additionally, stocks are more cost and technically efficient than public insurers. ${ }^{59}$ The results from the truncated regression analysis, displayed in Table 7, support the results discussed above.

These findings are not in line with the expense preference hypothesis and thus do not confirm Hypothesis 4, but they provide some support for the managerial discretion hypothesis. However, more empirical evidence is necessary before coming to any firm conclusion on this topic. For a detailed empirical analysis of the relationship between ownership form and efficiency for the German property-liability market, the reader is referred to Wende et al. ${ }^{60}$ who perform a comprehensive cross-frontier analysis for mutual, public and stock insurers. They find that each ownership form has comparative advantages in producing their own outputs, supporting a third hypothesis not discussed here - the efficient structure hypothesis.

\section{Specialisation}

The comparison of mean technical efficiency scores of specialised vs. non-specialised insurers (see Panel D of Table 6) shows little differences: technical efficiency scores are the same $(0.80)$ and cost efficiency scores are only slightly different ( 0.50 for specialised vs. 0.47 for non-specialised insurers). The truncated regression analysis, however, confirms that insurers focusing on one line of business are more cost efficient: the coefficient (see Panel B of Table 7) is significantly negative, indicating that specialised insurers' efficiency scores are closer to 1 and thus more efficient. This result supports the strategic focus hypothesis (see Hypothesis 5). Regarding the technical efficiency of specialised vs. diversified insurers, the truncated regression (see Panel A of Table 7) does not show any significant efficiency differences.

\footnotetext{
${ }^{58}$ Results from this analysis are available from the author upon request.

59 The size-stratified matching sample contains 133 firm years for each ownership form. Mutual insurers have a mean technical (cost) efficiency score of $0.96(0.80)$, public insurers of $0.90(0.68)$ and stock insurers of $0.93(0.72)$.

${ }^{60}$ Wende et al. (2008).
} 


\section{Leverage}

The results of our analysis of the relationship between financial leverage (proxied by the ratio of equity to total assets) and efficiency support the literature and Hypothesis 6: mean efficiency scores (see Panel E of Table 6) show significantly higher technical and cost efficiency scores for firms with above-median leverage. The truncated regression analysis confirms these results: coefficients are negative and significant.

\section{Growth}

Looking at the results as displayed in Panel F of Table 6, we see that mean technical and cost efficiency values for insurers with above-median growth are lower than for those with below-median growth ( 0.77 vs. 0.82 for technical efficiency and 0.47 vs. 0.50 for cost efficiency). The truncated regression analysis (Table 7) confirms this negative relationship for both technical and cost efficiency. Insurers with above-median premium growth have significantly lower efficiency values than those with belowmedian premium growth, as shown by the positive coefficients. These findings are in accord with Hypothesis 7.

\section{Conclusion}

The purpose of this paper was to provide a comprehensive analysis of efficiency in the German property-liability market, which has, due to its traditionally high level of regulation, been especially affected by recent deregulatory efforts.

Using a large unbalanced panel data set of 295 insurers for the years 1995-2006, cost, technical, allocative and scale efficiency scores were calculated employing DEA. We find that there is significant improvement potential: about 50 percentage points for cost efficiency and around 20 percentage points for technical efficiency. Moreover, low allocative efficiency scores indicate that one possibility for reducing costs is a change in the input mix. Labour inputs are most severely over-utilised, followed by debt and equity capital. Further analysis of returns to scale reveal that most of the larger insurers in the German property-liability market (about 90 per cent) operate under DRS, whereas most of the small (about 60 per cent) show IRS. This has important implications for potential merger activity in the market: efficiency gains are likely to be realised by small and medium-sized firms through mergers and acquisitions, but not by the large firms. However, due to already high levels of scale efficiency in the market, also for small insurers, overall potential from efficiency gains through mergers is limited.

As expected, the empirical analysis shows a positive development of TFP over time: TFP change is 8.2 per cent for 1995-2006. This is in line with what has been found for other markets, for example the Spanish insurance market, analysed by Cummins and Rubio-Misas, ${ }^{61}$ experienced a TFP growth of 8.7 per cent for the period 1989-1998.

\footnotetext{
${ }^{61}$ Cummins and Rubio-Misas (2006).
} 
One major contribution of this paper is the analysis of six efficiency determinants using a novel regression and bootstrapping approach as proposed by Simar and Wilson. ${ }^{62}$ We find a positive relationship between size and efficiency, that is large insurers are more efficient than medium-sized and small insurers. Furthermore, the analysis of different distribution systems shows that exclusive agent insurers are more efficient than independent agent insurers, which is in line with results for other markets such as the United Kingdom and the United States. With regard to the relationship between ownership and efficiency, mutuals are more efficient than stocks. Considering the impact of different degrees of specialisation on efficiency, there is evidence in support of the strategic focus hypothesis: specialised insurers are more cost efficient than those who spread their business across several lines. With regard to the effect of leverage on efficiency, there is a positive relationship. We find a negative relationship between premium growth and efficiency: strongly growing insurers are less efficient, which may be attributed to a lack in underwriting discipline in favour of growth aspirations.

Our results provide valuable insights into the structure and competitiveness of the German property-liability insurance market. Regulators should be particularly interested in the Malmquist Index results as well as the returns to scale analysis. Along with expectations, productivity and efficiency in the German property-liability market have increased during the past 11 years. Furthermore, mergers involving small and medium-sized companies should be encouraged from an efficiency point of view. For managers of German property-liability insurers, results from the analysis of efficiency determinants are of particular interest, as they provide some guidance with regard to important issues such as which distribution channel is most effective, whether or not to specialise and growth strategies.

There are a number of important issues left for future research. In particular, efficiency determinants should be analysed in more detail, for example through a cross-frontier analysis of distribution systems, testing whether independent agent and exclusive agent insurers operate with different technologies, or through a rigorous study of economies of scope for multiproduct vs. single product firms. Furthermore, the discussion of TFP change could be deepened, for example, by analysing cost and allocative efficiency changes, which are not captured by the Malmquist Index, based on alternative approaches as suggested by Maniadakis and Thanassoulis ${ }^{63}$ or GriffellTatjé and Lovell. ${ }^{64}$

\section{References}

Afonso, A. and Aubyn, M.S. (2006) 'Cross-country efficiency of secondary education provision: A semiparametric analysis with non-discretionary inputs', Economic Modelling 23: 476-491.

Barros, P., Barroso, N. and Borges, M.R. (2005) 'Evaluating the efficiency and productivity of insurance companies with a Malmquist Index: A case study for Portugal', The Geneva Papers on Risk and Insurance - Issues and Practice 30(2): 244-267.

\footnotetext{
${ }^{62}$ Simar and Wilson (2007).

${ }^{63}$ Maniadakis and Thanassoulis (2004).

${ }^{64}$ Griffell-Tatjé and Lovell (2000).
} 
Berger, A.N., Cummins, J.D. and Weiss, M.A. (1997) 'The coexistence of multiple distribution systems for financial services: The case of property-liability insurance', Journal of Business 70: 515-546.

Coelli, T.J., Rao, P.D.S., O’Donnell, C.J. and Battese, G.E. (2005) An Introduction to Efficiency and Productivity Analysis, Boston, MA: Kluwer Academic Publishers.

Cooper, W.W., Seiford, L.M. and Tone, K. (2007) Data Envelopment Analysis: A Comprehensive Text with Models, Applications, References and DEA-Solver Software, Boston, MA: Springer.

Cummins, J.D. and Nini, G.P. (2002) 'Optimal capital utilisation by financial firms: Evidence from the property-liability insurance industry', Journal of Financial Services Research 21: 15-53.

Cummins, J.D. and Rubio-Misas, M. (2006) 'Deregulation, consolidation, and efficiency: Evidence from the Spanish insurance industry', Journal of Money, Credit, and Banking 38: 323-355.

Cummins, J.D., Rubio-Misas, M. and Zi, H. (2004) 'The effect of organisational structure on efficiency: Evidence from the Spanish insurance industry', Journal of Banking and Finance 28: 3113-3150.

Cummins, J.D., Tennyson, S. and Weiss, M.A. (1999) 'Consolidation and efficiency in the U.S. life insurance industry', Journal of Banking and Finance 23: 325-357.

Cummins, J.D. and van Derhei, J.L. (1979) 'A note on the relative efficiency of property-liability distribution systems', Bell Journal of Economics 10: 709-719.

Cummins, J.D. and Weiss, M.A. (2000) 'Analysing firm performance in the insurance industry using frontier efficiency methods', in G. Dionne (ed) Handbook of Insurance Economics, Boston, MA: Kluwer Academic Publishers.

Cummins, J.D., Weiss, M.A. and Zi, H. (2007) Economics of scope in financial services: A DEA bootstrapping analysis of the U.S. insurance industry, working paper, The Wharton School, Philadelphia, PA.

Cummins, J.D. and Zi, H. (1998) 'Comparison of frontier efficiency methods: An application to the U.S. life insurance industry', Journal of Productivity Analysis 10: 131-152.

Diacon, S.R., Starkey, K. and O'Brien, C. (2002) 'Size and efficiency in European long-term insurance companies: An international comparison', The Geneva Papers on Risk and Insurance - Issues and Practice 27(3): 444-466.

Diboky, F. and Ubl, E. (2007) Ownership and efficiency in the German life insurance market: $A$ DEA bootstrap approach, working paper.

Eling, M. and Luhnen, M. (2008a) 'Understanding price competition in the German motor insurance market', Zeitschrift für die Gesamte Versicherungswissenschaft 97(Supplement): 37-50.

Eling, M. and Luhnen, M. (2008b) Frontier efficiency methodologies to measure performance in the insurance industry: Overview, systematisation, and recent developments, working paper, University of St. Gallen.

Erhemjamts, O. and Leverty, J.T. (2007) The demise of the mutual organisational form: An investigation of the life insurance industry, working paper.

Färe, R. and Grosskopf, S. (1996) Intertemporal Production Frontiers: With Dynamic DEA, Boston, MA: Kluwer Academic Publishers.

Fecher, F., Perelman, S. and Pestieau, P. (1991) 'Scale economics and performance in the French insurance industry', The Geneva Papers on Risk and Insurance - Issues and Practice 16: 315-326.

Fenn, P., Vencappa, D., Diacon, S., Klumpes, P. and O'Brien, C. (2008) 'Market structure and the efficiency of European insurance companies: A stochastic frontier analysis', Journal of Banking and Finance 32: 86-100.

Fuentes, H., Grifell-Tatjé, E. and Perelman, S. (2001) 'A parametric distance function approach for Malmquist Productivity Index estimation', Journal of Productivity Analysis 15: 79-94.

Greene, W.H. and Segal, D. (2004) 'Profitability and efficiency in the U.S. life insurance industry', Journal of Productivity Analysis 21: 229-247.

Griffell-Tatjé, E. and Lovell, C.A.K. (2000) 'Cost and productivity', Managerial and Decision Economics 21: $19-30$.

Hardwick, P. (1997) 'Measuring cost inefficiency in the U.K. life insurance industry', Applied Financial Economics 7: $37-44$.

Hussels, S. and Ward, D.R. (2006) The impact of deregulation on the German and U.K. life insurance markets: An analysis of efficiency and productivity between 1991-2002, Cranfield Research Paper Series (4), working paper.

Klumpes, P.J.M. (2004) 'Performance benchmarking in financial services: Evidence from the U.K. life insurance industry', Journal of Business 77: 257-274. 
Mahlberg, B. (1999) 'Effizienzmessung österreichischer und deutscher Versicherungen - Ein Vergleich', Wirtschaftspolitische Blätter 46: 400-406.

Mahlberg, B. (2000) 'Technischer Fortschritt und Produktivitätsveränderungen in der deutschen Versicherungswirtschaft', Jahrbücher für Nationalökonomik und Statistik 220(5): 565-591.

Mahlberg, B. and Url, T. (2000) The transition to the single market in the German insurance industry, working paper, Austrian Institute of Economic Research.

Maniadakis, N. and Thanassoulis, E. (2004) 'A cost Malmquist Productivity index', European Journal of Operational Research 154: 396-409.

Mayers, D. and Smith, C.W. (1988) 'Ownership structure across lines of property-casualty insurance', Journal of Law and Economics 31: 351-378.

Mester, L.J. (1991) 'Agency costs among savings and loans', Journal of Financial Intermediation 1: 257-278.

Rees, R., Kessner, E., Klemperer, P. and Matutes, C. (1999) 'Regulation and efficiency in European insurance markets', Economic Policy 14: 363-397.

Simar, L. and Wilson, P. (2007) 'Estimation and inference in two-stage, semi-parametric models of production processes', Journal of Econometrics 136: 31-64.

Trigo Gamarra, L. (2008a) The effects of liberalisation and deregulation on the performance of financial institutions: The case of the German life insurance market, working paper, University of Rostock.

Trigo Gamarra, L. (2008b) 'Reasons for the coexistence of different distribution channels: An empirical test for the German insurance market', The Geneva Papers on Risk and Insurance - Issues and Practice 33(3): 389-407.

Trigo Gamarra, L. and Growitsch, C. (2008) Single-versus multi-channel distribution strategies in the German life insurance market: A cost and profit efficiency analysis, working paper, University of Rostock.

Turchetti, G. and Daraio, C. (2004) 'How deregulation shapes market structure and industry efficiency: The case of the Italian motor insurance industry', The Geneva Papers on Risk and Insurance - Issues and Practice 29(2): 202-218.

Wende, S., Berry-Stölzle, T.R. and Lai, G.L. (2008) The effect of regulation on comparative advantages of different organisational forms: Evidence from the German property-liability insurance industry, working paper, University of Cologne.

Wilson, P.W. (2008a) FEAR 1.11 Command Reference, working paper, Department of Economics, Clemson University.

Wilson, P.W. (2008b) 'FEAR: A software package for frontier efficiency analysis with R', Socio-Economic Planning Sciences 42: 247-254.

Yuengert, A.M. (1993) 'The measurement of efficiency in life insurance: Estimates of a mixed normalgamma error model', Journal of Banking and Finance 17: 483-496.

\section{Appendix}

For the regression of contextual variables on efficiency, Algorithm \#1 of the procedure proposed by Simar and Wilson ${ }^{65}$ is used. It runs as follows: ${ }^{66}$

(1) Based on the original data, efficiency scores $\hat{\delta}_{i}$ are estimated for all observations $i=1, \ldots, n$ in the sample.

65 Simar and Wilson (2007).

${ }^{66}$ Note that Simar and Wilson (2007) also propose a second algorithm (Algorithm \#2), in which they additionally correct for bias in the DEA efficiency scores. This is especially important for small samples. In this paper, however, the bias correction is not performed because the sample is sufficiently large and, also, to avoid incurring the disadvantages related to the bootstrap needed for bias correction (see Coelli et al., 2005). 
(2) Estimates $\hat{\beta}$ of $\beta$ as well as $\hat{\sigma}_{\varepsilon}$ of $\sigma_{\varepsilon}$ are obtained through the truncated regression of $\hat{\delta}_{i}$ on a vector of contextual variables $z_{i}$ using the method of maximum likelihood and including the $m<n$ observations, where $\hat{\delta}_{I}>1 .^{67}$

(3) The next three steps are repeated $L$ times to obtain a set of bootstrap estimates $A=\left\{\left(\hat{\beta}^{*}, \hat{\sigma}_{\varepsilon}^{*}\right)_{b}\right\}_{b=1}^{L}$ :

(3.1) For each $i=1, \ldots, m, \varepsilon_{i}$ is drawn from the $N\left(0, \hat{\sigma}_{\varepsilon}^{2}\right)$ distribution with lefttruncation at $\left(1-z_{i} \hat{\beta}\right)$.

(3.2) Then, $\delta_{i}{ }^{*}=z_{i} \hat{\beta}+\varepsilon_{i}$ is computed for each $i=1, \ldots, m$.

(3.3) The maximum likelihood method is used to estimate the truncated regression of $\delta_{i}^{*}$ on $z_{i}$. The resulting estimates are $\left(\hat{\beta}^{*}, \hat{\sigma}_{\varepsilon}^{*}\right)$.

(4) The bootstrap values in $A$ and the initial estimates $\hat{\beta}, \hat{\sigma}_{\varepsilon}$ are used to construct confidence intervals for all elements in $\beta$ and for $\sigma_{\varepsilon}$.

\section{About the Author}

Michael Luhnen is a doctoral candidate at the University of St. Gallen, Switzerland, affiliated to the Institute of Insurance Economics. He studied business administration at the University of St. Gallen, Switzerland, majoring in Finance. He is a consultant at McKinsey \& Company, Inc., based in Zurich.

${ }^{67}$ Simar and Wilson (2007) scale efficiency values between 1 and infinity with 1 indicating 100 per cent efficiency. They exclude the fully efficient firms from the regression analysis. 